\title{
O papel de uma agência especial de seguros de empréstimos no Brasil*
}

The role of a special insurance agency for loans in Brazil

\author{
JOÃO SICSÚ ** \\ EDUARDO DA MOTTA E ALBUQUERQUE***
}

RESUMO: Este artigo sugere uma Agência Especial de Seguros (SIA) para o financiamento de investimentos inovadores. O objetivo desta agência é estabelecer um vínculo entre o sistema bancário e o sistema de inovação. Este artigo avalia o sistema bancário brasileiro e o sistema nacional de inovação e sugere uma inovação institucional. Essa Agência de Seguros Especiais apoiaria um aumento na quantidade de recursos privados alocados ao financiamento de atividades inovadoras, tanto para empresas estabelecidas quanto para novas empresas. Essa Agência de Seguros Especiais pode reorganizar a divisão do trabalho entre as instituições do sistema brasileiro de inovação.

PALAVRAS-CHAVE: Sistemas de inovação; sistemas financeiros.

ABSTRACT: This paper suggests a Special Insurance Agency (SIA) for the financing of innovative investments. The objective of this Agency is to establish a link between the banking system and the innovation system. This paper evaluates the Brazilian banking system and the national system of innovation and suggests an institutional innovation. This Special Insurance Agency would support an increase in the amount of private resources allocated to the financing of innovative activities, both for established firms and for new firms. This Special Insurance Agency might rearrange the division of labor among the institutions of the Brazilian system of innovation.

KEYWORDS: Innovation systems; financial systems.

JEL Classification: G2; O3.

\footnotetext{
* Os autores agradecem a Tales Andreassi pelo envio dos dados da ANPEI e pelos esclarecimentos que deu sobre os mesmos. Agradecem ainda a um parecerista anônimo pelos poucos, mas preciosos, comentários. Por último são reconhecidos os apoios da Fapemig, Faperj e do CNPq.

* * Professor Adjunto do Departamento de Economia da Universidade Federal Fluminense (UFF). e-mail: joaosicsu@gmail.com; Orcid: 0000-0003-3997-7129.

*** Professor Adjunto do Cedeplar da Universidade Federal de Minas Gerais (UFMG). e-mail: albuquer@ cedeplar.ufmg.br; Orcid: 0000-0002-1591-875X.
} 


\section{INTRODUÇÃO}

A imaturidade do sistema de inovação brasileiro foi amplamente avaliada. Dentre as mais importantes características dessa condição incompleta encontramse o percentual relativamente baixo de gastos com P\&D no país e o desperdício pelo setor produtivo de oportunidades oferecidas pela infra-estrutura científica. Essa avaliação implica o reconhecimento de possibilidades de implementação de reformas que viabilizem uma melhor alocação de recursos e um melhor aproveitamento de oportunidades.

Para esse quadro de escassez e desperdício contribui de forma sensível a incapacidade do sistema financeiro de financiar investimentos de longa duração e, em especial, investimentos inovativos. Portanto, inovações institucionais que respondam a essa importante lacuna devem ser investigadas. Este artigo sugere que a construção de uma Agência Especial de Seguros (AES) é uma inovação institucional que contribui para a superação da incapacidade do sistema financeiro brasileiro de financiar o investimento inovativo.

A idéia central deste artigo se apóia em trabalho anterior (Sicsú \& Albuquerque, 1998), que apresentou as bases teóricas da proposta de uma Agência Especial para segurar operações de financiamento de investimentos inovativos. A AES foi apresentada como uma decorrência da análise teórica realizada sobre as características particulares do investimento inovativo. O presente artigo discute especificamente o caso brasileiro, investigando a adequação dessa inovação institucional. Portanto, deve-se articular uma avaliação do sistema financeiro brasileiro com uma avaliação do sistema nacional de inovação. Da avaliação conjunta dos sistemas financeiro e inovativo do país, deriva-se a necessidade de uma inovação institucional que propicie um atalho para a solução de um grave problema estrutural.

$\mathrm{O}$ artigo está dividido em mais quatro seções. Na segunda, a dimensão industrial-tecnológica é discutida. Na terceira, a dimensão financeira é avaliada. $\mathrm{Na}$ quarta seção, a proposta da AES é sintetizada e os argumentos sobre a sua necessidade para contribuir para o amadurecimento do sistema de inovação brasileiro são apresentados. A quinta seção resume as conclusões do artigo.

\section{A DIMENSÃO INDUSTRIAL E TECNOLÓGICA}

Uma avaliação abrangente do sistema de inovação do Brasil pode ser compilada a partir de estudos abrangentes: Coutinho \& Ferraz (1995), Schwartzman (1993), Biato (1992) e Coutinho \& Suzigan (1990) apresentaram uma avaliação detalhada da estrutura industrial, do sistema de ciência e tecnologia e da infra-estrutura educacional do país. Uma compilação desses ricos estudos pode sustentar a avaliação do caráter imaturo do sistema de inovação brasileiro (Albuquerque, 1999). O dado mais revelador e sintético é a percentagem do PIB brasileiro destinado a atividades de P\&D: 0,8\%, enquanto a média dos países do G-7 encontra-se em $2,4 \%$. Outra diferença importante com os países mais avançados, é participação 
maior do setor público nas atividades de P\&D existentes no Brasil (aproximadamente $70 \%$ do total no caso brasileiro, contra $45 \%$ no caso americano e $20 \%$ no caso japonês, segundo dados de Nelson, 1993).

O sistema de inovação brasileiro encontra-se em uma situação intermediária no cenário internacional. Embora não faça parte do conjunto de países com sistemas de inovação inexistentes, possui características em comum com sistemas também incompletos. Por outro lado, o sistema brasileiro tem algumas características que são identificadas em países com sistemas maduros.

A partir de estatísticas de patentes (Albuquerque, 2000), foi possível identificar características em comum com países mais avançados: 1 ) firmas nacionais (privadas e estatais) como líderes na obtenção de patentes; 2 ) indícios de firmas multitecnológicas; 3) distribuição do número de patentes em forma de "U" de acordo com o tamanho da firma; 4) elasticidade intersetorial P\&D-patentes compatível com os valores encontrados na literatura (Bound et alli, 1984).

Características comuns a outros sistemas imaturos foram encontradas: 1) participação elevada das patentes de indivíduos; 2) baixo envolvimento das firmas em atividades inovativas; 3) falta de continuidade das atividades de patenteação; 4) baixa sofisticação da divisão de trabalho inter-firmas; 5) papel declinante do setor produtor de bens de máquinas e equipamentos; 6) caráter predominantemente adaptativo das atividades tecnológicas das firmas estrangeiras; 7) diferenças entre a patenteação no INPI e no USPTO (United States Patent and Trademark Office), indicando que alguns setores que são líderes na patenteação interna praticamente desaparecem nas estatísticas do escritório norte-americano de patentes.

Um aspecto particular da imaturidade do sistema de inovação brasileiro, característica comum a outros sistemas também imaturos, como o da Índia e do México (Albuquerque, 1999), é de especial interesse aqui: o desperdício de oportunidades criadas pela infra-estrutura pública de pesquisa. Para uma avaliação geral da relação entre a atividade científica e a atividade tecnológica, é possível utilizar um indicador de aproveitamento de oportunidades (IAO) (Albuquerque, 1997). Esse indicador é construído a partir de duas proxies. A primeira é a participação relativa do país no total mundial de artigos científicos publicados: uma proxy das atividades científicas do país. A segunda é a participação relativa no total de patentes concedidas pelo USPTO: uma proxy das atividades tecnológicas executadas pelo país em questão. Ambas as proxies têm problemas (para artigos, ver Velho, 1987; para patentes ver Griliches, 1990), mas contêm valiosas informações.

O IAO é calculado dividindo-se a participação relativa no total de patentes concedidas pelo USPTO pela participação relativa no total mundial de artigos científicos $^{1}$. Qual o significado do IAO? Dada a complexidade da relação entre

\footnotetext{
${ }^{1}$ Sendo o indicador de aproveitamento de oportunidade o resultado de uma divisão entre duas participações relativas (\% patentes mundiais/\% artigos mundiais), seguramente ele carrega todos os problemas metodológicos e estatísticos discutidos na literatura sobre patentes e artigos. Alguns problemas devem ser inclusive ampliados, pela forma como o indicador é composto. Esses problemas recomendam cautela na apreciação dos resultados obtidos.
} 
ciência e tecnologia, a comparação entre as duas participações relativas deve apresentar indícios da qualidade da interação entre elas. A avaliação da interação entre a ciência e a tecnologia é um aspecto importante da avaliação dos sistemas de inovação. A suposição básica, derivada da fundamentação teórica dos sistemas nacionais de inovação, é a de que firmas, universidades e centros de pesquisa devam ter um grau razoável de interação. Caso haja um fosso grande entre essas instituições constitutivas do sistema de inovação, isto deve se refletir em um baixo nível de inter-conectividade do sistema. O IAO pode contribuir para oferecer pistas sobre a qualidade dessas conexões. A Tabela I apresenta o indicador de aproveitamento de oportunidades para um conjunto selecionado de países.

\begin{tabular}{cc} 
Tabela I: Indicador de Aproveitamento de Oportunidades (IAO) por país (19) \\
\cline { 2 - 2 } País & IAO \\
\hline Japão & 2,7 \\
Coréia do Sul & 2,6 \\
Estados Unidos & 1,5 \\
Alemanha & 1,2 \\
Suíça & 1,2 \\
França & 0,6 \\
Holanda & 0,5 \\
Reino Unido & 0,4 \\
México & 0,26 \\
Brasil & 0,15 \\
Argentina & 0,06 \\
Índia & 0,01 \\
\hline
\end{tabular}

Fonte: USPTO (1994), Scientometrics (1994) (elaboração própria).

Para o tema deste artigo, o ponto importante na avaliação do indicador de aproveitamento de oportunidades é a posição do sub-conjunto no interior do qual está localizado o caso brasileiro: o Brasil encontra-se entre os países de IAO mais baixo, inferiores a 0,26 (ao lado de México, Argentina e Índia, todos países com sistemas imaturos). É importante notar que os países mais desenvolvidos têm IAO maior, sendo que os países que fizeram processos de catching up no século XX (Japão e Coréia do Sul) possuem os IAOs mais elevados. No caso dos Estados Unidos, há um razoável equilíbrio entre as produções científicas e tecnológicas (IAO $=1,5)$.

Com relação aos sistemas imaturos, a participação do setor científico é razoavelmente superior à produção do setor industrial-tecnológico, determinando o IAO baixo. Daí deriva-se o diagnóstico da existência de desperdício de oportunidades. Em termos agregados, o conjunto da infra-estrutura científica parece estar gerando informações e conhecimento não-utilizados de forma apropriada pelo setor industrial e tecnológico.

Dessa avaliação sumária do estágio de construção do sistema de inovação no país, duas questões particulares cobram da interface com o sistema financeiro res- 
postas originais. Em primeiro lugar, há a necessidade de ampliação dos gastos nacionais com P\&D, com destaque para um envolvimento maior e mais sistemático das firmas privadas nessas atividades. Em segundo lugar, o potencial existente nas atividades da infra-estrutura científica do país sugere a necessidade de instrumentos que possam reduzir o desperdício de oportunidades diagnosticado anteriormente.

\section{A DIMENSÃO FINANCEIRA}

Um elemento importante da imaturidade do sistema de inovação brasileiro é a baixa articulação existente com o sistema financeiro. O sistema financeiro, aliás, possui uma incapacidade estrutural de conceder financiamentos de longa duração. Esta seção avalia essa incapacidade estrutural e discute se as mudanças que o sistema financeiro tende a sofrer no país representarão a superação de tal incapacidade.

\subsection{Uma Avaliação}

O investimento em P\&D envolve algumas especificidades técnicas e econômicas que têm determinado a forma de seu financiamento. São características do investimento em P\&D, o seu longo período de maturação e a necessidade de um volume elevado de recursos. Tais características geram uma aguda incerteza devido aos riscos técnicos e de mercado envolvidos ${ }^{2}$. O elevado volume de recursos necessários deveria induzir as firmas inovadoras a solicitar recursos de terceiros. Contudo, os elevados riscos tendem a inibir as firmas inovadoras a recorrer a essas fontes. A opção de grande parte das firmas, mundo afora, tem sido pelo autofinanciamento, já que, além dos fatores que inibem a demanda, a oferta de recursos para o financiamento externo é reduzida ou, até mesmo, é inexistente - em decorrência das incertezas envolvidas.

Segundo Zysman (1983), há três sistemas de financiamento do investimento, em geral, e conseqüentemente, do investimento inovativo: os sistemas de mercados de capitais, os sistemas de crédito privado e os sistemas de crédito público. O primeiro modelo pode ser exemplificado especialmente pela forma de financiamento do investimento nos Estados Unidos e na Inglaterra. Nesses países, é privilegiado o canal do financiamento direto via emissão de papéis (ações, debêntures etc.)

\footnotetext{
${ }^{2}$ A especificidade do investimento empresarial em P\&D deriva diretamente do grau de incerteza que este tipo de investimento está envolvido. Além das variáveis-incertas presentes quando da decisão de investir em bens de capital, tais como a demanda futura, o investimento em P\&D para ser bem-sucedido depende de novas variáveis. Ao decidir comprar uma máquina para produzir uma mercadoria $\mathrm{X}$, o empresário enfrenta a incerteza, por exemplo, quanto à demanda por essa mercadoria (risco de mercado). Quando, porém, esse empresário decide contratar uma equipe de pesquisadores para inventar uma nova máquina para produzir a mesma mercadoria X, enfrenta novas incertezas: o desenlace da atividade de pesquisa pode levar ou não àquela nova máquina desejada (risco técnico). Ademais, a invenção pode ter gerado uma nova máquina não-competitiva. $\mathrm{O}$ esforço de $\mathrm{P} \& \mathrm{D}$, portanto, pode ser considerado um investimento de caráter especial, um investimento denso de incerteza.
} 
pela firma investidora que busca captar os recursos do público poupador. No segundo sistema, os bancos provêm as firmas de crédito de longo prazo; esse é caso da Alemanha. No terceiro sistema, à semelhança do segundo, o governo garante a oferta de crédito de longo prazo. Instituições públicas, tais como bancos de desenvolvimento e agências de fomento, realizam tal oferta, como é o caso da França. Alternativamente, o governo pode, em lugar de participar diretamente do sistema de financiamento, impor uma série de regras para dirigir o sistema de crédito privado para o financiamento de longo prazo; esse é o caso do Japão.

O sistema brasileiro de financiamento de recursos para o investimento em P\&D é basicamente de autofinanciamento, não encontra lugar na taxonomia de Zysman (1983). Em relação aos gastos com P\&D, de 1993 a 1998, os recursos investidos foram basicamente autofinanciados e somente uma reduzida parcela foi financiada por fontes externas que são as agências públicas (BNDES, Finep etc.), as agências internacionais, o Sebrae, os bancos privados e outras fontes que subsidiam ou praticamente doam recursos para este fim. O Gráfico I mostra que nesse período, 199398 , a parcela autofinanciada dos recursos investidos nunca foi inferior a 90\% (a fonte dessas informações é a base de dados da Associação Nacional de P,D\&E das Empresas Inovadoras - ANPEI) ${ }^{3}$. Embora os dados fornecidos pela ANPEI não revelem, sabe-se que as fontes externas são fundamentalmente fundos fiscais e créditos oficiais e que, certamente, a participação dos bancos privados deve ser quase nula no financiamento do investimento inovativo.

Gráfico I: Percentual de Fontes Externas

e Autofinanciamento do Investimento em P\&D

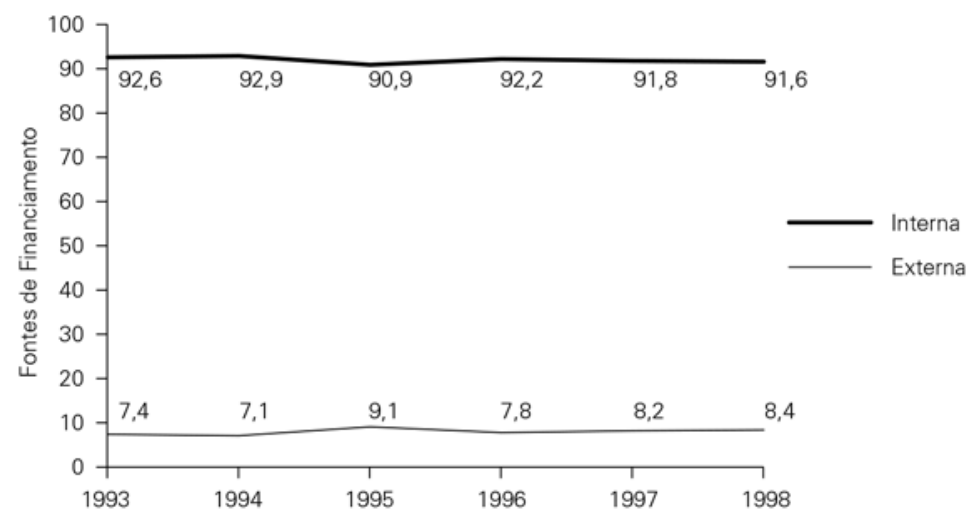

Fonte: Anpei.

\footnotetext{
${ }^{3}$ A base de dados da ANPEI possui uma amostra bastante representativa. Em média, 450 empresas responderam o questionário a cada ano. Tais empresas têm faturamento bruto que corresponde a $41 \%$ do PIB industrial do Brasil. As empresas da amostra estão em média distribuídas da seguinte forma: $70 \%$ no sudeste, $20 \%$ no sul, $8 \%$ no nordeste e $2 \%$ nas demais regiões.
} 
Isto ocorre no Brasil porque o mercado de capitais e, especificamente, o mercado de ações é bastante débil, assim como não existe uma vocação do sistema financeiro brasileiro para se transformar em um sistema de crédito, em qualquer das versões destacadas na classificação de Zysman (1983). Cabe ressaltar, portanto, que até mesmo o investimento não-inovativo é fortemente autofinanciado na economia brasileira. Segundo Lees, Bott e Cysne (1990), durante os anos 1980, a parcela dos gastos que foi autofinanciada nas empresas privadas nacionais era de aproximadamente $77 \%$, ao passo que as empresas privadas estrangeiras utilizavam quase que $88 \%$ de recursos próprios para financiar os seus gastos.

A causa da debilidade do mercado de ações é basicamente o reduzido volume de poupança com perfil de longo prazo que poderia dar densidade a esses mercados. Por exemplo, os fundos de investimento, administrados pelos bancos, são compostos pelo FIF (fundo de investimento financeiro), por fundo de ações e outros — tais fundos, desde que foram criados, no início dos anos 1990, são compostos, em grande medida, por títulos federais e uma reduzida parcela de ações. Nos primeiros meses do ano 2000, segundo dados do Boletim do Banco Central, mais de $70 \%$ do volume de recursos dos fundos de investimento estavam direcionados para a aquisição de títulos federais e aproximadamente $8 \%$ para a aquisição de ações.

No Gráfico II, tem-se mais um indicador da debilidade do sistema financeiro brasileiro. Pode-se observar que há uma acentuada tendência de elevação da participação percentual do volume de crédito concedido aos setores que caracteristicamente tomam recursos para operações de curto prazo (pessoas físicas e comércio) no período junho de 1988 a outubro de 1999 em relação ao total de crédito concedido pelo sistema financeiro. De forma oposta, a participação percentual do volume de recursos emprestado pelo sistema financeiro aos setores que caracteristicamente tomam crédito de longo prazo (indústria e habitação) apresenta uma ligeira tendência de queda no mesmo período.

Nem mesmo o Plano Real, instituído em julho de 1994, alterou essas tendências, muito embora tenha criado um clima muito mais favorável às atividades reais de longo prazo, como a construção de moradias e infra-estrutura e o investimento de ampliação ou de constituição de novas plantas. Em resumo, as tendências indicadas no Gráfico II mostram que o sistema financeiro brasileiro não tem se mostrado capaz de desempenhar as funções exercidas pelos sistemas de crédito privado ou público identificados por Zysman.

Se são reduzidas as poupanças com perfil de longo prazo no Brasil, os sistemas de crédito (privado e público, na sua versão japonesa) também não podem ser uma alternativa, porque as instituições financiadoras (para conceder crédito de longo prazo) não podem carregar passivos curtos ${ }^{4}$. Como se pode observar no Gráfico III, a partir de linhas de tendência, a participação percentual dos depósitos a prazo no total do passivo dos bancos comerciais era muito baixa no final dos anos 1980

\footnotetext{
${ }^{4}$ A versão francesa do sistema de crédito público também não pode ser uma opção viável porque o governo brasileiro, como é de amplo conhecimento, não possui capacidade de realizar gastos.
} 
Gráfico II: Participação Percentual do Crédito Concedido

à Indústria/Habitação e Pessoas Físicas/Comércio em Relação ao

Total de Crédito Ofertado pelo Sistema Financeiro (junho/1988 a outubro/1999)



Fonte: Banco Central do Brasil.

para sustentar a concessão de crédito de longo prazo. Contudo, cabe ressaltar que os bancos comerciais não possuem horizontes de longo prazo. Os bancos múltiplos, estes sim, que possuem um estrutura de ativos e passivos mais diversificada, poderiam atuar com horizontes maiores. Entretanto, o percentual de participação dos depósitos a prazo nos seus passivos, no final dos anos 1980, era inferior ao percentual alcançado pelos bancos comerciais.

O crescimento acentuado dos depósitos a prazo no passivo dos bancos múltiplos e comerciais que ocorreu até 1994 não foi devido ao aumento da propensão a poupar em ativos de longo prazo, mas simplesmente porque esses eram ativos que protegiam os recursos monetários de seus possuidores em um contexto de inflação alta e crônica e, além disso, seu prazo de resgate era bastante reduzido, por vezes, dependendo do volume de recursos e de outras condições impostas pelos bancos, podiam ser resgatados em apenas um dia. O que pode ser observado é que após a estabilização, a partir de julho de 1994, o percentual de depósitos a prazo em relação ao total do passivo dos bancos múltiplos e comerciais volta a declinar atingindo patamares semelhantes àqueles do final dos anos 1980 . A única diferença é que recentemente os bancos múltiplos estão captando depósitos a prazo em proporção maior (relativamente ao total de seus passivos) do que os bancos comerciais.

A ausência de poupadores de longo prazo também se deve a fatores associados ao sistema financeiro. Por exemplo, a inexistência de instituições captadoras de grande porte e com tradição que gozem da confiança do público potencialmente poupador de recursos a longo prazo e, paralelamente, a inexistência de mecanismos reconhecidamente eficazes de proteção das poupanças (isto é, mecanismos de controle de riscos das operações das instituições captadoras) podem ser considerados fatores inibidores da realização de poupanças de longo prazo ${ }^{5}$.

\footnotetext{
${ }^{5}$ Não é objetivo do artigo investigar os motivos que explicam a ausência de poupança de longo prazo
} 
Gráfico III: Participação Percentual dos Depósitos a Prazo no

Passivo dos Bancos Múltiplos e Comerciais - 1988-1999

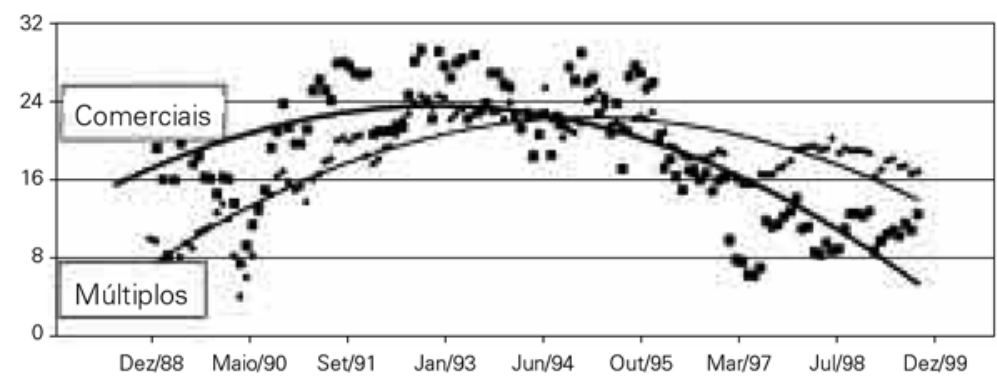

Fonte: Banco Central do Brasil.

\subsection{Perspectivas para o Financiamento do Investimento em P\&D}

Nada indica que esse quadro tenderá a mudar. Pelo contrário, a tendência do sistema financeiro internacional, a qual será seguida no Brasil devido à entrada de um grande número de bancos estrangeiros no país a partir de 1995, deverá manter ou agravar a situação de precariedade do financiamento ao investimento em P\&D. A tendência do sistema financeiro internacional é o aprofundamento do processo de desintermediação financeira e o alargamento dos mercados de dívidas securitizadas. Desintermediação é o termo utilizado para designar o processo que os bancos estão há algum tempo desenvolvendo, principalmente nos Estados Unidos, em que reduzem suas operações de concessão de crédito e, simultaneamente, ampliam o volume de operações menos arriscadas de realização de negócios diretos entre poupadores e investidores - tais operações são chamadas de securitização.

A emissão de papéis por parte de firmas investidoras para a aquisição direta por parte de instituições poupadoras com perfil de longo prazo é um tendência crescente do sistema financeiro internacional e, além disso, é uma tendência alternativa ao sistema de crédito privado e público em que as instituições carregam o risco inerente das operações de concessão de empréstimos e os seus custos mais elevados - devido às restrições regulatórias (reservas mínimas) e às formas específicas desses negócios (por exemplo, o estudo de cadastro). Essas operações não são recentes, as grandes corporações e instituições poupadoras de longo prazo já participam dos mercados de dívidas há muitos anos. As empresas menores ou que realizam investimentos com maiores risco não têm tido acesso a essa fonte porque não possuem a tecnologia dos negócios desse mercado ou porque representam um elevado risco para o poupador (emprestador).

Sendo assim, quando o processo de desintermediação ocorrer no Brasil, tal

no país. Mostra-se tão-somente que a inexistência desse tipo específico de poupança é um dos fatores que reduzem as possibilidades do sistema financeiro de apoiar o investimento tradicional e inovativo. Interessantes argumentos sobre a ausência de poupança de longo prazo podem ser encontrados em Hermann (1998). 
transformação muito provavelmente não mudará a situação de escassez do investimento em P\&D. As empresas investidoras em P\&D, aos olhos dos poupadores, continuarão a emitir papéis com possibilidades bastante arriscadas de negócios recompensadores e, certamente, a tomada de recursos para este fim, ainda que seja em uma operação direta com o poupador, representará uma possibilidade de financiamento em que o risco do emprestador tende a ser maior do que para projetos não-inovativos. Ainda que exista demanda por financiamento para o investimento inovativo e exista oferta de fundos para a concessão de empréstimos, a taxa de juros de tal operação seria bastante elevada devido ao risco de inadimplência, o que tenderá a inviabilizar os empréstimos.

O Gráfico IV mostra esquematicamente o que se espera que ocorra com o financiamento do investimento inovativo com a implementação da desintermediação e da securitização no Brasil. O eixo vertical representa a taxa de juros (i) e o eixo horizontal, o volume de investimento (I) financiado diretamente pela poupança (S) de longo prazo. A curva $S_{1}$ representa a oferta de poupança de longo prazo da economia e a curva $\mathrm{I}_{1}$ representa o investimento convencional (que possui um risco menor vis-a-vis o investimento inovativo). A quantidade de poupança A1 está disponível para financiar o investimento de mesma magnitude a uma taxa de juros inferior a $\mathrm{i}^{*}$. Os poupadores não aceitam financiar projetos de investimento a uma taxa de juros superior a $i^{*}$ porque o risco de inadimplência de projetos tecnicamente mais arriscados torna-se maior quando o seu empreendedor terá que pagar uma taxa de juros muito elevada. Em outras palavras, projetos arriscados não se tornam financiáveis quanto maior é a taxa de juros que o tomador está disposto a pagar, há um limite máximo que os poupadores consideram aceitável. Acima do limite não há negócios seguros para os emprestadores.

Gráfico IV: O Mercado de Dívidas Securitizadas e o Financiamento do Investimento Inovativo



A curva $\mathrm{I}_{1}+\mathrm{I}_{2}$ é a soma da curva $\mathrm{I}_{1}$ com uma curva que representa projetos mais arriscados (por exemplo, investimentos inovativos). Sua inclinação é ligeiramente 
diferente da curva $\mathrm{I}_{1}$ exatamente porque os projetos são mais arriscados, assim seus empreendedores não desejam se comprometer com uma taxa de juros mais elevada. Em contrapartida, a curva de oferta de poupança é quebrada para cima a partir do ponto A1 porque os poupadores cobram uma taxa de juros mais elevada para financiar projetos menos seguros. Então, a quantidade de financiamento de projetos mais arriscados não seria A4-A1, mas sim A2-A1, que neste caso, por mera coincidência, seria cobrada a taxa limite $i^{*}$. Se uma quantidade maior de financiamento para projetos mais arriscados fosse demandada, o que pode ser representado pela curva $\mathrm{I}_{1}+\mathrm{I}_{2}+\mathrm{I}_{3}$ (que é paralela a curva $\mathrm{I}_{1}+\mathrm{I}_{2}$ ), não seria financiada porque interceptaria a curva de oferta de poupança a uma taxa superior à taxa limite $\mathrm{i}^{*}$. Portanto, o investimento total não seria A3, mas tão-somente A2.

$\mathrm{O}$ que se pode concluir é que a única mudança que se vislumbra que possa ocorrer no sistema financeiro brasileiro, a desintermediação e a implementação da securitização, não poderá alterar de forma substancial o quadro atual de escassez de demanda e oferta de fundos para o financiamento do investimento inovativo. Cabe alertar, no entanto, que a questão da reduzida demanda por atividades de inovação não seria integralmente resolvida se os problemas decorrentes do sistema de financiamento fossem solucionados. Como foi visto na seção 2, há problemas que necessitam ser superados e que pertencem essencialmente ao sistema de inovação.

\section{A AGÊNCIA ESPECIAL DE SEGUROS COMO UMA INOVAÇÃO INSTITUCIONAL PARA O BRASIL}

A discussão das duas seções anteriores identificou a imaturidade do sistema de inovação brasileiro, indicando a singular combinação entre escassez (de gastos em P\&D) e desperdício (de oportunidades geradas a partir da infra-estrutura científica) e a incapacidade do sistema financeiro em financiar o investimento inovativo. A questão agora é investigar como ampliar os recursos investidos em atividades inovativas sem ter que desviar recursos públicos para financiar o setor privado e sem deslocar recursos comprometidos com a infra-estrutura pública de ciência para a iniciativa privada.

Qualquer economia funciona à base de regras, impostas por suas instituições, que influenciam diretamente a conformação das expectativas dos agentes. As instituições, na prática, são um conjunto de regras que estabelecem punições e incentivos que afetam as motivações e decisões dos agentes. O funcionamento de uma economia de mercado é compatível com uma ampla diversidade institucional, algumas são deletérias, outras são virtuosas. As incertezas envolvidas nos processos de financiamento de atividades de P\&D somente serão reduzidas na presença de instituições de suporte aos agentes. Em outras palavras, uma instituição capaz de reduzir ou socializar os riscos financeiros das atividades de P\&D é um rede de segurança social. Tal rede reduz as incertezas porque limita os ganhos daqueles que, por ventura, tenham suas expectativas confirmadas pela realidade e reduz a perda 
daqueles cujas expectativas foram decepcionadas. A Agência de Seguros proposta é uma rede de segurança social.

É importante salientar que existem um conjunto de instituições, programas e projetos que tentam suprir as debilidades da relação existente entre o sistema de inovação e o sistema financeiro. Campelo (2000) realizou um levantamento detalhado das instituições envolvidas com financiamento e apoio à atividade inovativa no Brasil. A avaliação geral apresentada anteriormente sobre a imaturidade do sistema de inovação no Brasil é um diagnóstico da incapacidade dessas importantes tentativas em superar os problemas apontados na seção 2. Por isso, a proposta da AES justifica-se.

Certamente o sistema de inovação brasileiro tem muito a ganhar com mais recursos públicos investidos diretamente em suas instituições. O que este artigo busca é dar uma contribuição para essa possibilidade, ao explicitamente, propor que recursos públicos não sejam destinados para apoiar o setor privado. Em suma, tratase de investigar uma instituição que contribua para ampliar os recursos que o setor privado investe em atividades inovativas. Para tanto, o objetivo deve ser o de criar mecanismos que estimulem o envolvimento do setor financeiro privado com as atividades inovativas - e não os recursos públicos.

Deixado à própria sorte, o sistema financeiro brasileiro não desenvolverá as características necessárias para o financiamento do investimento inovativo. A proposta de uma AES foi apresentada como uma sugestão para superar um problema identificado a partir da avaliação das características do investimento inovativo. Trata-se agora de justificar por que essa Agência é necessária e adequada para o caso brasileiro.

\subsection{Um Resumo da Proposta da AES}

Sicsú \& Albuquerque (1998, pp. 687-9) sintetizaram a proposta da AES. Os argumentos principais, extraídos daquele texto, são os que se seguem. ${ }^{6}$

Dadas as condições de incerteza inerentes às atividades de P\&D que geram reduzidos financiamentos para estas atividades e o conseqüente subinvestimento neste segmento da economia, sugere-se a intervenção do setor público. O objetivo dessa intervenção seria minimizar tais condições desfavoráveis, dado que o mercado é incapaz de minorá-las. Propõe-se a criação de uma Agência Especial de Seguros que realize algum tipo de seguro não-tradicional dos financiamentos dos investimentos privados em P\&D. A Agência pagaria uma indenização ao banco emprestador, que recuperaria uma parcela dos recursos comprometidos caso o projeto fracassasse por razões estritamente tecnológicas. O objetivo seria pagar uma indenização que satisfizesse parte da demanda por segurança desejada pelo investidor potencial em $P \& D$ e por seu financiador. O pagamento de uma indenização

\footnotetext{
${ }^{6}$ Para a fundamentação teórica da AES, os trabalhos de Freeman (1982), Arrow (1971) e Borch (1990), dentre outros, foram utilizados.
} 
muito abaixo das necessidades do potencial-inovador e de seu financiador inibiria a decisão de investir; por outro lado, uma indenização muito elevada desestimularia os esforços necessários ao sucesso do projeto implementado, assim como incentivaria análises bancárias pouco rigorosas sobre o projeto de P\&D. Uma indenização estratégica, isto é, intermediária (entre aquele valor que inibe a atividade e aquele outro que desestimula e/ou reduz o rigor de análise) seria o ideal. ${ }^{7}$

A AES seria constituída inicialmente por um aporte de recursos públicos, inaugurando um fundo, que seria por ela administrado. A partir de sua constituição, tal fundo seria alimentado por recursos privados, decorrentes dos pagamentos que empresários inovadores devem fazer à AES para garantir o direito de seguro de suas operações financeiras relacionadas às suas atividades inovadoras. Espera-se que a proporção de recursos privados cresça ao longo do tempo. O aporte inicial e constitutivo de recursos públicos tem um papel-chave para a construção da credibilidade da AES. Caso a parcela de recursos de origem pública do fundo venha a ser utilizada, isso indicaria a existência de graves problemas no funcionamento geral do sistema de inovação e de seu financiamento - dado que a AES não estaria atraindo recursos privados. A AES, nesse caso, não estaria conseguindo resolver os problemas que motivaram a sua criação. É importante lembrar que as atividades da AES estão entre as atividades do tipo long-tail, isto é, atividades cujo resultado negativo (o sinistro) apenas pode ocorrer depois de um certo período de tempo, o que fornece à AES uma importante margem de manobra inicial. ${ }^{8}$

A entidade proposta para compor o sistema financeiro é uma Agência por ser uma instituição semi-autônoma no interior do Estado que administrará recursos privados de acordo com objetivos públicos (não terá como meta a obtenção de lucros). A entidade proposta é Especial porque não é uma seguradora que aposta contra eventos cuja distribuição de probabilidades existe e é conhecida. É uma Seguradora porque embora não o seja no sentido estrito do termo, a AES acabará por ser vista por banqueiros e empresários como uma instituição seguradora tradicional que paga indenizações em caso de fracasso. ${ }^{9}$

Por último, a proposição da AES é decorrente da concepção que não considera apropriadas políticas que sugerem a transferência direta de recursos governamentais para firmas privadas. (Nelson \& Romer, 1996) Tal política poderia resultar em uma indevida redução da participação do setor público na necessária sustentação da infra-estrutura científica. Esta possui um papel crucial na divisão de trabalho interinstitucional existente nos sistemas de inovação, ao garantir um

\footnotetext{
${ }^{7}$ Alguns outros argumentos sobre a determinação do prêmio, o valor da indenização e os custos para a implementação do sistema de seguro de empréstimos para a inovação aparecem em Sicsú \& Albuquerque (1998). Contudo, reconhece-se que essas são questões que merecem ser aprofundadas porque delas depende a viabilidade da AES.

${ }^{8}$ Para a diferenciação na literatura sobre seguros entre atividades long-tail e short-tail, ver Meier (1988).

${ }^{9}$ Os sistemas de seguros de depósito bancário (tais como o modelo Federal Deposit Insurance Corporation - FDIC - nos Estados Unidos), embora não constituam seguradoras tradicionais, são dessa forma vistos por depositantes e banqueiros.
} 
pólo da complexa interação entre ciência e tecnologia. Portanto, a discussão teórica realizada sobre o caráter do financiamento do investimento em P\&D foi combinada com uma preocupação adicional: como ampliar os gastos globais em P\&D sem comprometer o financiamento do lado inescapavelmente público do sistema de inovação.

A sugestão da criação dessa agência é estimulada por trabalhos como de Miranda et alli (1998), que estimula estudos sobre "novos instrumentos financeiros" para a viabilização da obtenção de recursos pelo setor produtivo. Com a criação da AES e o seu bem-sucedido funcionamento, até mesmo operações que envolvessem diretamente poupadores e investidores poderiam ser beneficiadas dado o clima propício à realização de investimentos inovativos que emergiria. Por exemplo, a curva $S_{1}$ do gráfico IV teria possivelmente sua quebra mais suave para constituir a curva $S_{1}+S_{2}$, isto ampliaria os recursos ofertados para o financiamento das atividades de P\&D.

\subsection{A Inserção da AES no Sistema de Inovação Brasileiro}

O sistema de inovação brasileiro necessita de uma AES porque o sistema financeiro não tem sido capaz de financiar o investimento inovativo. A AES deve contribuir para que o sistema financeiro construa uma ponte com o sistema de inovação. Porém, a discussão do caso brasileiro sugere que a AES deve ser organizada de forma a dar conta das duas questões indicadas ao final da seção 2: a) ampliar os gastos com P\&D pelo setor privado e b) fortalecer as possibilidades de transformação do conhecimento gerado/absorvido pela infra-estrutura científica em atividades industriais e tecnológicas (o que significa apoio ao desenvolvimento de novas firmas de base tecnológica).

Por isso, a proposta feita anteriormente deve ser ligeiramente adaptada para as tarefas específicas de um sistema imaturo. Essas envolvem a necessidade de inovações institucionais tanto para ampliar o envolvimento do setor bancário com investimentos inovativos (que é a base da proposta sintetizada na subseção 4.1 como para dar conta de maior apoio ao surgimento de novas e potenciais firmas tecnologicamente dinâmicas. No caso de um sistema imaturo como o brasileiro (com um baixo IAO, conforme a seção 2), o apoio ao surgimento de novas firmas pode ser um canal importante para um melhor aproveitamento dos conhecimentos gerados a partir da infra-estrutura pública de pesquisa.

$O$ envolvimento da AES no processo de financiamento para o surgimento de novas firmas tecnológicas justifica-se teoricamente porque os empréstimos para a abertura de novas firmas podem ser considerados (no esquema da seção 3) mais arriscados do que empréstimos para uma firma estabelecida. Uma firma estabelecida possui ativos, receitas futuras etc. que podem servir de colateral em empréstimos, ativos que faltam para uma firma que está sendo criada. Por isso, em linhas gerais, esse tipo de operação envolve uma parcela de risco semelhante à do investimento inovativo. $\mathrm{E}$ os resultados de investimentos bem-sucedidos nessa área têm repercussões econômicas similares às de investimentos inovativos em geral. 
No caso brasileiro, essas tarefas corresponderiam às tarefas desempenhadas pelo esquema britânico do loan guarantee scheme (LGS) (Goodcare \& Tonks, 1996; National Economic Research Associates, 1990; Levitsky \& Prasad, 1987). Esse esquema foi mencionado em Sicsú \& Albuquerque (1998, pp. 689-90) para apoiar a argumentação da AES. As especificidades do caso brasileiro justificam a inclusão das atividades do LGS entre as funções da AES. Assim, seria também função da AES conceder facilidades a uma operação específica; isto é, no caso brasileiro, a AES buscaria ampliar tanto os empréstimos do setor bancário para investimentos inovativos de firmas existentes como empréstimos para a criação de novas firmas tecnologicamente dinâmicas.

Essa situação precária dos sistemas de inovação e financeiro tem sido percebida pela comunidade tecnológica e de formuladores de políticas públicas no país. Inúmeras tentativas de resolver esse impasse têm surgido: financiamentos a fundo perdido, experiências de incubadoras tecnológicas, financiamentos subsidiados, programas como o da Fapesp de apoio à inovação industrial. ${ }^{10}$ Porém, esses programas apresentam um conjunto de problemas. Por exemplo, muitas vezes buscam replicar no Brasil experiências bem-sucedidas em outros países, sem muito esforço para adaptá-las às condições específicas do país (esse talvez seja o caso das incubadoras e de algumas referências ao capital de risco - venture capital). Ademais, essas iniciativas podem ampliar distorções existentes, ao colocar uma instituição de apoio à infraestrutura de ciência para apoiar iniciativas industriais, o que seria papel de outro tipo de agente (bancos de fomento, talvez). A retirada de recursos públicos (escassos) para a sua canalização a fundo perdido para o setor privado não fortalece a divisão interinstitucional de trabalho inerente aos sistemas de inovação. Como discutido na seção anterior, a criação da AES pretende exatamente evitar essa problema alocativo.

A criação de uma AES rearranja o sistema de inovação brasileiro em quatro dimensões. Em primeiro lugar, a AES constrói uma ponte entre o sistema financeiro e o sistema de inovação, criando condições para que o setor privado canalize recursos para atividades inovativas e para a criação de novas firmas de base tecnológica. Que recursos seriam usados para a alavancagem inicial da AES (a criação do Fundo inicial)? A idéia básica é aproveitar recursos existentes: o fundo inicial da AES pode ser constituído pelo remanejamento de recursos. Existem fundos compulsórios disponíveis na economia brasileira, que representam de 1 a 3\% do PIB brasileiro (Pinheiro, 1998, p. 13). Uma parcela desses recursos poderia ser alocada por um número determinado de anos para a constituição inicial do fundo. Além disso, recursos públicos dispersos que atualmente são utilizados para financiar esse tipo de atividade poderiam também ser deslocados para a construção inicial do fundo.

\footnotetext{
${ }^{10}$ Fapesp está lançando o sétimo edital do Programa de Inovação Tecnológica em Pequenas Empresas (PIPE). "Somando os projetos da primeira e segunda fase, a Fapesp investiu a fundo perdido R \$ 8,6 milhões e US\$2,4 milhões desde o final de 1997. Para este ano, está programando o investimento total de R\$ 10 milhões para o PIPE” (Fapesp, 2000, p. 42).
} 
Em segundo lugar, a entrada dos bancos privados no processo de financiamento de atividades inovativas deve ser considerada um importante passo em direção ao amadurecimento do sistema de inovação. $\mathrm{O}$ desenvolvimento de capacidade de avaliação, monitoramento e fiscalização de empréstimos para atividades de enorme impacto econômico certamente representa uma importante mudança estrutural de um sistema financeiro incapaz de sair de um limitado horizonte de curto prazo.

Em terceiro lugar, o setor público tem o papel-chave no financiamento e no aprimoramento da infra-estrutura científica do país. A criação da AES retira de entidades voltadas para o fomento da atividade científica a responsabilidade de injetar recursos para a viabilização do aproveitamento comercial de novos conhecimentos. ${ }^{11}$

Em quarto lugar, as agências que hoje aprovam projetos e destinam recursos para novas firmas e atividades inovativas (Finep, BNDES, SEBRAE, Fapesp etc.) têm uma contribuição importante para a constituição da AES: o know-how acumulado na avaliação de projetos e de sua viabilidade será útil para a preparação da capacidade técnica que a AES precisa ter (tal como descrito na subseção 4.1). Nesse sentido, mesmo os bancos privados podem se beneficiar dessa capacitação já acumulada. Haveria um remanejamento de tarefas no interior dessas instituições. Os bancos privados necessitariam desenvolver novas habilidades de avaliação de projetos, para desenvolver a capacidade de selecionar de forma apropriada projetos de investimentos em P\&D por firmas existentes e de criação de novas firmas. Pessoal treinado em avaliação desse tipo de projetos poderia se deslocar para os bancos privados, o que contribuiria para ampliar os horizontes dessas instituições. As agências de fomento à atividade científica e tecnológica poderiam, assim, se concentrar nas tarefas de ampliar a capacidade científica do país em áreas selecionadas, deixando ao complexo AES e bancos privados a busca e avaliação de oportunidades para investimentos lucrativos. Finalmente, os bancos de fomento, poderiam concentrar suas tarefas na execução de políticas industriais visando ao amadurecimento do sistema de inovação brasileiro e o fortalecimento do sistema de bem-estar social.

Enfim, a criação da AES reorganiza o sistema de inovação brasileiro, ampliando o número de agentes atuando no sistema de inovação e definindo uma divisão de trabalho inter-institucional mais precisa.

\section{CONCLUSÃO}

A proposta de uma inovação institucional caracterizada pela criação de uma AES parte de uma avaliação do estágio de construção do sistema de inovação bra-

\footnotetext{
${ }^{11}$ Embora a AES seja uma instituição que pode ser criada para tirar a responsabilidade do setor público de injetar recursos em atividades de aproveitamento comercial de inovações, não deve ser encarada como uma instituição que isenta o setor público de dirigir o processo. Nesse sentido, a AES poderia, até mesmo, ser anexada à Finep, como um de seus departamentos ou entidade coligada.
} 
sileiro e do grau de funcionalidade do sistema financeiro. É importante destacar que o caráter imaturo do sistema brasileiro de inovação enfatiza a existência de elementos que devem ser utilizados para o seu amadurecimento. Em especial, a infra-estrutura científica constituída é um importante ponto de partida. A presença de firmas (e não indivíduos) como líderes na patenteação é uma outro ponto de partida importante.

Por outro lado, o sistema financeiro brasileiro, em que pese as limitações discutidas no texto, é expressivo. Existem instituições bancárias poderosas que possuem condições de cumprir um papel crucial de apoio a um processo de desenvolvimento.

A proposta da AES, portanto, é adequada ao estágio atual de construção tanto do sistema de inovação como do sistema financeiro, pois basicamente busca o estabelecimento de uma ponte entre ambos. Construída essa ponte, um enorme passo em direção ao amadurecimento do sistema de inovação brasileiro terá sido dado.

Finalmente, deve ser mencionado que a proposta da AES tem sentido para a atual fase do desenvolvimento brasileiro. Certamente, durante os anos 1970, em função dos estágios ainda mais rudimentares do sistema de inovação, essa proposta não teria a sustentação que hoje encontra. O sistema de inovação, ao longo dos anos 1970 e 1980, completou o desenvolvimento da atual infra-estrutura científica e um núcleo de firmas ativas se consolidou (o peso das patentes concedidas para indivíduos residentes no Brasil pelo USPTO caiu de 76,2\% do total em 1980 para $22,2 \%$ do total em 1995). Portanto, é uma tarefa atual o estabelecimento de uma ponte entre o sistema de inovação e o sistema bancário, ponte que pode criar uma espécie de circuito virtuoso e sustentável entre ambos.

\section{REFERÊNCIAS BIBLIOGRÁFICAS}

ALBUQUERQUE, E. (1997) "Notas sobre os determinantes tecnológicos do catching up: uma introdução à discussão sobre o papel dos sistemas nacionais de inovação na periferia”. Estudos Econômicos, 27(2).

ALBUQUERQUE, E. (1999) “National systems of innovation and non-OECD countries: notes about a tentative typology”. Revista de Economia Política, 19(4): 35-42.

ALBUQUERQUE, E. (2000) "Domestic patents and developing countries: arguments for their study and data from Brazil (1980-1995)”. Research Policy, 29(9), november 2000: 1047-1060.

ARROW, K. (1971). Essays in theory of risk-bearing. Amsterdam/London: North Holland.

BIATO, F. A. (coord.) (1992). Estudos analíticos do setor de ciência e tecnologia. Brasília/MCT.

BORCH, K, H. (1990). Economics of Insurance. Amsterdam: North Holland.

BOUND, J., CUMMINS, C., GRILICHES, Z., HALL, B., JAFFE, A. (1984). "Who does R\&D and who patents?". In: Griliches Z. R\&D: Patents and Productivity. Chicago: The University of Chicago.

CAMPELO, P.G. (2000) Investimento inovativo: a questão do financiamento. Dissertação de Mestrado. Niterói: Universidade Federal Fluminense (UFF).

COUTINHO, L. \& FERRAZ, J. C. (coords.) (1995) Estudo sobre a competitividade da indústria brasileira. Campinas: Papirus/UNICAMP.

COUTINHO, L. \& SUZIGAN, W. (1990) Desenvolvimento tecnológico da indústria e a constituição de um sistema nacional de inovação. Campinas: IE/UNICAMP.

FAPESP (2000) "Aumentam recursos para inovação". Pesquisa, 53, maio. 
FREEMAN, C. (1982). The Economics of Industrial Innovation. London: Prances Pinter.

GOODCARE, A.; TONKS, I. (1996) "Finance and technological change". In: STONEMAN, P. (eds.) Handbook of the economics of innovation and technological change. Cambridge: Basil Blackwell.

GRILICHES, Z. (1990) "Patent statistics as economic indicators: a survey". Journal of Economic Literature, $28: 1.661-1.707$.

HERMANN, J. (1998). “Financiamento de Investimentos no Brasil”. In: Oliveira, A. \& Pinto Jr., H. Financiamento do Setor Elétrico Brasileiro. Rio de Janeiro: Editora Garamond.

LESS, F., BOTTS, J. CYSNE, R. (1990). Banking Financial Deepening in Brazil. New York: St. Martin's. LEVITSKY, J.; PRASAD, R. (1987) "Credit guarantee schemes for small and medium enterprises”. Washington: World Bank Technical Paper, 58.

MEIER, K (1988) The political economy of regulation: the case of insurance. New York: State University of New York.

MIRANDA, R. B.; RODRIGUES JÚNIOR, W.; SILVA, M. M. (1998) "Intermediação de poupança para investimento no setor produtivo”. Brasília: IPEA, Texto para Discussão 597.

NATIONAL ECONOMIC RESEARCH ASSOCIATES (1990). "An Evaluation of the Loan Guarantee Scheme". Research Paper prepared for the Department of Employment, $\mathrm{n}^{\circ}$ 74, London.

NELSON, R. \& ROMER, P. (1996). "Science Economic Growth, and Public Policy”. Challenge, MarApr: 9-21.

NELSON, R. (1993). National Innovation Systems: a comparative analysis. New York: Oxford University.

PINHEIRO, M. M. S. (1998) "Fundos de poupança compulsória e financiamento da economia: 1990/ 1997”. Brasília: IPEA, Texto para Discussão 588.

SCHWARTZMAN, S. (1993) Ciência \& tecnologia no Brasil: uma nova politica para um mundo global. São Paulo: FGV/EAESP, 1993 (Série Ciência e Tecnologia no Brasil).

SICSÚ, J. \& ALBUQUERQUE, E. (1998) "Financiamento do investimento em P\&D, risco e seguro: uma abordagem não-convencional". Revista Brasileira de Economia, 52(4): 675-96.

VELHO, L. (1987) "The author and the beholder: how paradigm commitments can influence the interpretation of research results". Scientometrics, 11(1-2): 59-70, Jan.

ZYSMAN, J. (1983). Governments, Markets and Growth: Financial Systems and the Politics of Industrial Growth. New York: Cornel. 